\title{
O LINEAMENTO SISMO-TECTÔNICO DE CABO FRIO
}

\author{
GEORG ROBERT SADOWSKI* e CORIOLANO DE M. DIAS NETO*
}

\begin{abstract}
The Cabo Frio lineament was defined as a continental expression of a ridge offset formed during the separation of the continents. It coincides with a line of seismic activity, with several alkalines of Senonian and Paleocene age, and with disruptive structures. Historical and recent earthquakes were located by intensity and instrumental data. The alkaline lineament coincides with a Senomian-Paleocene plate trajectory obtained through back rotation of the continents along the poles defined by Ladd (1975). Geochronologically the alkalines show a trend of lower ages towards the east. These features indicate a possible existence of a hot spot type mechanism in this area associated with the major mesozoic thermal Ponta Grossa-Mossamedes swell.
\end{abstract}

INTRODUÇÃO O alinhamento leste-oeste da costa do Rio de Janeiro já chamou a atenção de diversos pesquisadores, entre os quais Francheteau e Le Pichon (1972), March (1973), Rideg (1974), Almeida (1976), etc. Sadowski (1976 e 1980) já focalizou a importância dos lineamentos continentais subparalelos às falhas transformantes do oceano, nos quais inclui este lineamento.

Os presentes autores examinam este lineamento dentro do conceito de tectônica de placas, visando à definição de um modelo tectônico relativamente coerente.

O lineamento de Cabo Frio apresenta as seguintes feições que o tornam distinto dentro do contexto geológico em que se situa:

a) Constitui uma importante zona de deflexão da costa associada ao limite norte da bacia costeira de Santos, já aventada por Francheteau e Le Pichon (1972).

b) Apresenta no continente paralelismo com uma certa deflexão leste-oeste-nordeste de estruturas pré-cambrianas e mais recentes, já notada por Rideg (1974), e por ele atribuída à falha de Taxaquara, mas que também é notória no falhamento de Jacutinga.

c) Dentro do oceano apresenta uma possível extensão na forma da zona de fratura de $42^{\circ} 50^{\prime}$ de Francheteau e Le Pichon (1972), ou Rio de Janeiro (Asmus, 1978).

d) É sublinhado pelo alinhamento de alcalinas, mais recentes que 80 milhões de anos (m.a.) Cabo Frio-Poços de Caldas.

e) Apresenta sismicidade preferencial ao longo de sua trajetória definida pelo método de isossistas e por dados de aparelhos (Assumpção et al., 1980).

CONTEXTO GEOLÓGıCO No continente, as rochas são constituídas essencialmente por metamorfitos pré-cambrianos de alto grau, fortemente deformados e cortados por cinturões de cisalhamento dúctil e friável (Sadowski, 1980). As direções de dobramento e de cisalhamento são regionalmente N50-60E, sofrendo uma certa deflexão horária ao longo de uma linha Além $\mathrm{Pa}$ raíba-Pinhal nas imediações da borda sul do Craton de
São Francisco. Grabens de idade terciária preenchidos por sedimentos terciários e quaternários com direção NE ocorrem na região, definidos como Graben do Paraíba e da Guanabara por Almeida (1976).

Introduzidas nas rochas do Cristalino ocorrem em caráter regional rochas alcalinas de idade que variam de 132 a 51 m.a. (Amaral et al., 1967). Estas intrusões estendem-se desde o Paraná até o Rio de Janeiro e definem dois máximos de idades: um, a 120 m.a. e, outro, a 80 m.a., correspondendo, respectivamente, à época de separação dos continentes e a um evento de mudança do pólo de rotação das placas Sul-Americana e Africana (Sadowski, 1976).

Dentro do contexto de vulcanismo alcalino geral desta parte do continente, as alcalinas situadas ao longo do lineamento apresentam posição excepcional, dada a sua baixa idade relativa, indicando fenômenos vulcânicos posteriores aos restantes na região do geotumor Ponta Grossa-Mossamedes, de Le Bas (1971).

As alcalinas em consideração foram estudadas dentro do contexto geocronológico por Amaral et al. (op. cit.): as de Poços de Caldas, Itatiaia, Tinguá, Pico de Marapicu, Casimiro de Abreu, Rio Bonito e Cabo Frio. Outras, dentro do contexto geocronológico similar, foram definidas recentemente (Ulbrich e Gomes, inédito).

No oceano, paralelizando localmente o lineamento, a Petrobrás definiu uma falha de gravidade que constitui parte do abatimento de aproximadamente $11 \mathrm{~km}$, definido por Almeida (1976), entre o embasamento da Bacia de Santos e o alto da superfície de aplainamento dos Altos Campos. Esta falha faria parte do complexo disruptivo que limita setentrionalmente a Bacia de Santos. Mais para o interior do oceano, Asmus (1978) cita a zona de fratura do Rio de Janeiro que seria, eventualmente, a estrutura de ordem maior associada. Cabe lembrar que esta zona de fraturamento oceânico apresenta uma largura correspondente a uma faixa leste-oeste que ocorreria entre São Sebastião e Cabo Frio, se superposta ao continente. 


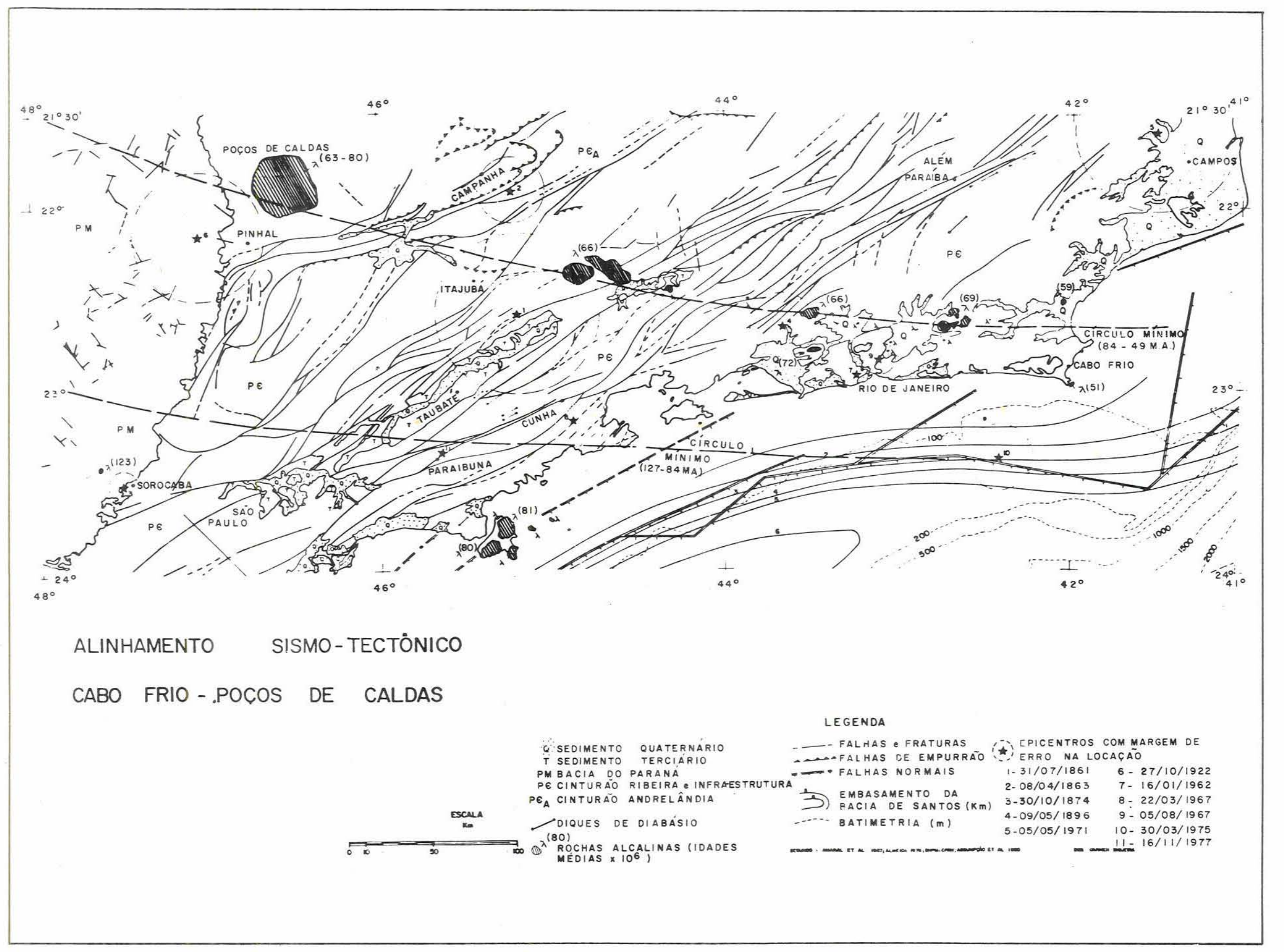


Aspectos Geocronológicos As correlações de idade até agora feitas por autores anteriores para esta região têm-se baseado nas idades médias propostas por Amaral et al. (1967). Se analisarmos os dados geocronológicos, temos que considerar, como seus autores, que idades de piroxênios e de feldspatos têm fornecido valores anômalos, cuja explicação não nos caberia no presente contexto. Conseqüentemente, resolvemos considerar como mais representativas as idades potássio-argônio obtidas de biotitas e algumas idades de rocha total mais novas, correspondentes a diques diversos, relacionadas a temperaturas de esfriamento mais baixas.

Tal tratamento permite considerar as idades dentro de um contexto mais homogêneo. No entanto, devemos lembrar que se trata em geral de idades mínimas de resfriamento e não de idades de formação.

O uso de idades melhor filtradas permitiria, talvez, definições mais precisas dos eventos vulcânicos permitindo caracterizar melhor a natureza do lineamento proposto.

Dentro dessa conceituação, consideramos como passíveis de análise dentro do trabalho as idades de 80 m.a. para Poços de Caldas, 66 para Itatiaia, 60 para Tinguá e 49 para Cabo Frio. Obviamente, vemó-nos obrigados a admitir que um maior número de análises seria necessário para melhor definir os padrões de idade.

Aspectos Cinemáticos Desde a abertura dos continentes, os mesmos sofreram rotações associadas às respectivas placas, ao redor de aproximadamente cinco posições de pólos de rotação, determinadas por Ladd (1975) pelo método consagrado de Pitman e Talwani (1972). Por conseguinte, as trajetórias de movimentação não foram sempre as mesmas, ou apenas duas como se pensou inicialmente.

Em nosso trabalho, efetuamos a reconstrução da posição dos continentes por rotação inversa até a junção das placas, definindo as posições das trajetórias de rotação respectivas para cada intervalo de tempo geológico. A trajetória, ou círculo mínimo do período de abertura válida para o pólo de 127 a 84 m.a., corresponde curiosamente à direção da costa na região de Cabo Frio, conforme foi previsto por Francheteau e Le Pichon. A trajetória, referente ao pólo de nosso interesse, ou seja, correspondente ao período entre 84 e 49 m.a., coincide aproximadamente, após efetuadas as correções de rotação correspondente ao período anterior, ao alinhamento de alcalinas Poços de Caldas-Cabo Frio (ver o mapa).

Calculando-se a velocidade de deslocamento da placa Sul-Americana ao longo desta última trajetória, dentro do período de idades compreendido pelo vulcanismo acima citado, e considerando-se um ponto quente fixo inicialmente em Poços de Caldas, obtemos para uma distância de $475 \mathrm{~km}$ uma velocidade de 1,5 cm/ano. A velocidade de deslocamento da placa Sul-Americana para o período de 72 a 49 m.a. dentro do qual cai a maioria das alcalinas do lineamento foi de $1,8 \mathrm{~cm} /$ ano calculado por Ladd (1974).

Tal coincidência, apesar das imprecisões inerentes às datações e aos erros menores acumulados, permite considerar esses dados como indicativos de um modelo tipo ponto quente dentro, do modelo cinemático proposto, diferindo assim de outros modelos eventuais propostos de anomalias de manto fixas ou móveis (por exemplo, Herz, 1977) para a área.

Sismicidade da Área Com base em dados macrossísmicos e instrumentais, Assumpção et al. (1980) estudaram a sismicidade da Região Sudeste do Brasil. Uma curiosa concentração dos epicentros dos sismos mais intensos determinados por esses autores, pelo traçado de isossistas na maioria dos eventos, ocorre ao longo deste lineamento (ver o mapa). Esses sismos, cujas imprecisões na locação de epicentros variam de 3 a $50 \mathrm{~km}$, apresentaram magnitudes (mb) de 3,2 (1962) a 5,1 (1922).

A ocorrência histórica e atual desses eventos permite supor a continuidade do tectonismo neste linear, assim como Sbar e Sykes (1978), Fletcher et al. (1976) e Sykes (1978) definiram para lineamentos similares em outras partes do globo.

CONCLUSÕES A superposição de eventos geológicos do Meso-Cenozóico e atuais, representados por intenso magmatismo alcalino e relativa sismicidade, respectivamente, confere a esta faixa um caráter anômalo dentro de um contexto regional.

A curiosa coincidência do círculo mínimo de abertura do Atlântico Sul, válido no período $84-49$ m.a., com os corpos alcalinos com idades neste mesmo intervalo, sugere uma interligação desses fenômenos a favor de um modelo tipo ponto quente.

Esta anomalia teria associação com estruturas da borda continental submersa e da plataforma continental, incluindo a sismicidade atual. É possível uma associação com a zona de fratura do Rio de Janeiro, definida pela Petrobrás como crosta oceânica.

Em relação às alcalinas meso-cenozóicas, os autores não descartam a possibilidade da existência de um mecanismo do tipo ponto quente em atividade na área do final do Mesozóico ao início do Cenozóico, associado ao geotumor Mossamedes-Ponta Grossa. No entanto, chamam a atenção que outros alinhamentos correlatos de alcalinas bordejam setentrionalmente a Bacia do Paraná (Hasui et al. 1975). Neste alinhamento, a cronologia não parece ser sintomática do mesmo mecanismo.

Trabalhos adicionais sobre essa estrutura visando definir a dinâmica desses alinhamentos dentro de um contexto rigoroso de geocronologia seriam de grande interesse para aprimorar a formulação do modelo de evolução local.

Agradecimentos À Fundação de Amparo à Pesquisa do Estado de São Paulo (FAPESP), pela colaboração recebida. 


\section{BIBLIOGRAFIA}

ALMEIDA, F I.M - 1976 - The system of continental rifts bordering the Santos Basin, Brazil. Continental Margins of Atlantic Type. Am. Acad. Bras. Ciencias 48 (Supl.), 15-26.

AMARAL, G., BUSHEE, J., CORDANI, U.G., KAWASHITA, K. e REY. NOLDS, J.H. - 1967 - Potassium-Argon ages of alkaline rocks from southern Brazil. Geochim, et Cosmochim. Acta 31: 117-142.

ASMUS, H.E. - 1978 - Hipóteses sobre a origem dos sistemas de zonas de fratura occânica/alinhamentos continentais que ocorrem nas regið̌es Sudeste e Sul do Brasil. Projeto REMAC n. 4, pp. 39-73, Rio de Janeiro.

ASSUMPCÃO, M., DIAS NETO, C.M., BERROCAL, J., ANTEZANA, Rl, FRANCA, H e ORTEGA, R - 1980 - Sismicidade do Sudeste do Brasil. XXXI Cong. Bras. Geol, Camboriu, vol. 2: 1075-1092.

FLETCHER, J.B., SBAR, M.L. e SYKES, L.R. -1976 - Seismic trends and travel-time residuals in castern North America and their tectonic implications. Geol. Soc. Am. Bull. (no prelo)

FRANCHETEAU, J c LE PICHON, X - 1972 - Marginal fracture zones as structural frantework of continental margin in South Atlantic Ocean. AAPG Bull., 56(6): 991-1007.

HASUI, Y., CARNEIRO, C.D.R. e COIMBRA, A.M. - 1975 - The Ribeira folded belt. Rev. Bras. Geoc. 5(4): 257.266.

HASUI, Y., SADOWSKI, G.R., SUGUIO, K, e FUCK, G.F. - 1974 - Phanerozoic tectonic evolution of the Western Minas Gerais State, Brasil. Anais Academia Bras. de Ciências, 47: 431-438.

HERZ, N. - 1977 - Tuning of spreading in the South Atlantic. Geol. Soc. Am. Bull. 88: $101-112$
LADD, J.W. - 1974 - South Atlantic sea-floor spreading and Caribbean tectonics. Columbia University, Ph.D. Thesis, $200 \mathrm{pp}$.

LE BAS, M.J. - 1971 - Pre-Alkaline volcanism, crustal swelling, and rifting Nature, Physical Sci. 230: 85-87.

MARSH, J.R. - 1973 - Relationship between transform directions and alkaline igneous rocks lineaments in Africa and South America. Earth Planet-Sci. Lett., 18: $317-23$.

PITMAN, W.C. e TALWANI, M. $-1972-$ Sea-floor spreading in the North Atlantic. Geol. Soc. Am. Bull. 83(3): 619-649.

RIDEG, P. - 1974 - Ubatuba lineament: identification of new pre-rift feature. AAPG Bull, , 58: 2362-2366.

SADOWSKI, G.R. - 1976 - Ativaçao de Plataforma na América do Sul e as zonas de fratura do Atlântico Sul". 29: Congresso Brasileiro de Geologia, Belo Horizonte 4: 13-19.

SADOWSKI, G.R -1980 - Platformal activation and the South Atlantic fracture zones, $26^{\text {th }}$ International Geological Congress, Paris. Abstracts Vol. 1.

SADOWSKI, G.R. - $1980-$ Brazilian pan african shear belts. $26^{\text {th }}$ International Geological Congress, Paris. Abstracts Vol. 1.

SBAR, M.L e SYKES, R.L - 1976 - Contemporary compressive stress and seismicity in eastern North America: An example of intra-plate tectonics. Geol. Soc. Am. Bull. 84: 1861-1882.

SYKES, L.R. - 1978 - Intraplate seismicity, reactivation of preexisting zones of weakness, alkaline magmatism, and other tectonism post-dating continental fragmentation. Rev. Geophys. and Space Phys. 16(4): 621-688. 